\title{
Uma prática projetual de sinalização do Centro Universitário de Volta Redonda - UniFOA.
}

\section{A Practical Case in Centro Universitário de Volta Redonda - UniFOA's Sign System.}

\author{
Cristiana de Almeida Fernandes ${ }^{1}$ \\ Marcos Vinícios Esteves da Silva Marcelino ${ }^{2}$ \\ Danton Gravina Baêta Rodrigues ${ }^{2}$ \\ Carla Fernandes de Lima ${ }^{2}$ \\ Matheus Moraes Amorim Pereira ${ }^{2}$
}

Artigo

Original

Original

Paper

\begin{abstract}
Palavras-chave: Resumo
Acessibilidade $\quad$ O objetivo deste artigo é documentar a produção acadêmica de um projeto de sinalização que visou à adequação ao grande fluxo de circulação diária dentro do Centro Universitário de Volta Redonda - UniFOA-. Compartilhando as informações obtidas, auxiliam-se outros estudantes de design a contribuir para a melhoria da qualidade de vida de seu entorno, viabilizando uma melhor localização dos usuários dentro de suas universidades
\end{abstract}

\section{Key words:}

Accessibility

Sign

Legibility.

\section{Apresentação}

O curso de Design do UniFOA foi implantado há dois anos por uma necessidade empresarial da Região Sul Fluminense. Existe um "sem número" de indústrias que necessitam agregar valor competitivo aos seus produtos e o diferencial produtivo está intimamente relacionado ao Design1. Atualmente, o setor empresarial regional dedica-se ao beneficiamento do aço em virtude da cultura do segmento a partir da cidade de Volta Redonda, com a presença da CSN - Companhia Siderúrgica Nacional, porém, poucas veem no produto final uma possibilidade de extensão de seu negócio.

A equipe para execução desse projeto foi escolhida pela orientadora, buscando alunos que se encaixassem ao perfil e que estivessem predispostos a ceder parte do seu tempo para elaboração desse sistema de sinalização. Aliás, é proposta acadêmica do curso, que as habilidades sejam trabalhadas, como forma de valorizar o potencial criativo de cada discente. (UNIFOA:2009)

Ao fazer parte desse processo, foi adquirida pelos alunos uma experiência, julgada pelos próprios, de grande utilidade em suas carreiras, pois, foi vivenciado um projeto real, quando o mercado atual exige amplo conhecimento acerca de recursos úteis e responsabilidade com prazos. Foi estabelecida uma meta para entrega do projeto que deveria ser contemplado em dois meses. A partir desse marco, foi proposto um cronograma metodológico de trabalho, aplicado às 
realidades institucionais, em que nenhum tipo de projeto similar havia sido executado anteriormente pelo curso ou pela Instituição.

O nascimento desse processo de sinalização se deu ao fato de algo essencial: acessibilidade. Quando nos referimos à acessibilidade, não pensamos apenas em pessoas portadoras de necessidades especiais, mas sim em todos os indivíduos que necessitam se locomover e se localizar dentro de um ambiente: "a acessibilidade visa proporcionar a maior quantidade possível de pessoas, independentemente de idade, estatura ou limitação de mobilidade ou percepção, a utilização de maneira autônoma e segura do ambiente, edificações, mobiliário, equipamentos urbanos e elementos". (NBR-9050/04)

O UniFOA é um Centro Universitário que recebe, diariamente, cerca de cinco mil pessoas, entre elas, alunos, professores, funcionários e visitantes. Há dentro do Campus Três Poços, de 25 a 30 áreas de acesso, sendo algumas específicas para funcionários, como garagem, manutenção e cozinha. Para o público visitante, existem duas agências bancárias, três auditórios para eventos, sendo um deles destinado a realizações culturais. Para os acadêmicos, as áreas vão desde estacionamentos, passando por salas de aula, laboratórios, cantinas e áreas de convivência, como biblioteca, salas de estudos e praças.

Após circular nos campi do Centro Universitário de Volta Redonda - UniFOA, que tem sua sede na cidade de Volta RedondaRJ, consultar alunos, professores, funcionários e visitantes, nota-se que a primeira circulação só é possível através de alguém que conhece bem o local. Os usuários necessitam de um guia, pois a configuração atual da sinalização não atende às necessidades dos usuários; não há clareza nas informações contidas nas placas atuais. Surge então, a oportunidade de contribuir para a melhoria do acesso à informação pelos usuários em um novo projeto de sinalização do Campus, a partir de uma proposta de atividade de extensão pelo curso de Design.

O ponto de partida da proposta foi a adoção de uma fotografia aérea do Campus Olezio Galotti (figura 1), que permitiu a contabilidade de prédios e áreas de importância, definindo assim fluxos de circulação viária em um infográfico2. É necessário, neste momento, esclarecer que o modelo adotado para o projeto foi o de placas de acesso viário3, que auxiliassem na melhor localização dos usuários dentro do Campus universitário, não levando em consideração a circulação interna aos prédios e áreas, nem os fatores ligados ao mapeamento de risco4. Tais modelos já existem em proposta e devem ser abordados em outro projeto, pela complexidade e quantidade de informações, que deve ser contemplado ao sistema de identidade visual adotado para esse estudo de sistema de sinalização.

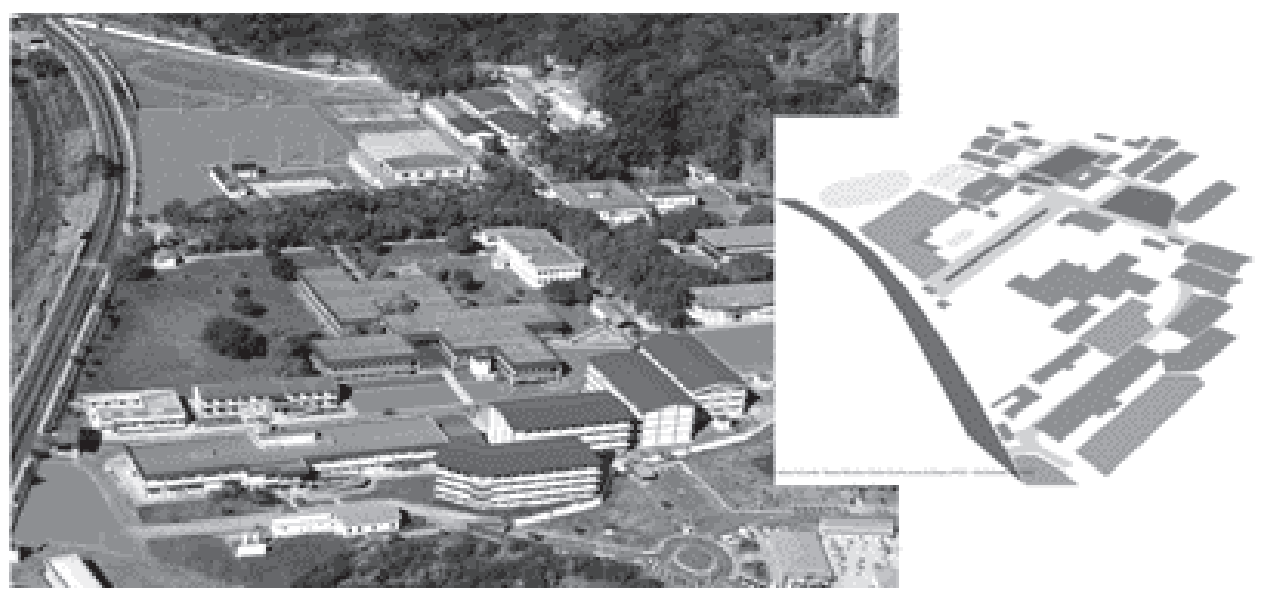

Figura 1 - infográfico da foto aérea do Campus Universitário 


\section{Parte 1: Problematização}

A partir do levantamento das placas presentes no Campus Três Poços, foi constatado que a configuração atual da sinalização não atende à necessidade dos usuários, pois têm problemas avaliados em diversas categorias descritas logo abaixo:

\section{1:Ergonomia.}

Não há como falar em adaptação de projetos aos usuários sem recorrer aos recursos oferecidos pelos estudos da Ergonomia.

\begin{abstract}
“(...) para que o design contribua significativamente para o desenvolvimento de produtos que sejam adequados aos usuários de um modo que eles reconheçam e achem satisfatório e prazeroso, necessitam-se de métodos para entender os usuários e as mudanças que influenciam suas vidas. Para fazer isto, devemos estender nossas noções de ergonomia para incluir um espectro mais amplo de influências sobre qualquer usuário potencial". (HESKETT:1993)
\end{abstract}

No caso em questão, a necessidade de adequação do projeto é bem ampla e deve ser funcional, na sinalização atual existem placas alocadas em espaços de difícil identificação, onde, de uma certa distância, principalmente visualizando a partir de veículos, é difícil a leitura das informações, principalmente porque o tamanho das letras, bem como a fonte escolhida, não facilitam um bom entendimento. As alturas mínimas das letras necessárias para visibilidade, segundo regras determinadas pelo CONTRAN5, são dadas em função da distância de visibilidade. A necessidade desse distanciamento é de, no mínimo $10 \mathrm{M}$, pois é a área definida entre o usuário e a placa, dentro das áreas de circulação no Campus.

\section{2: Legibilidade.}

A configuração atual dessa sinalização também possui um problema em sua legibilidade. Não é possível compreender, a certa distância, o conteúdo das placas, pois o tamanho da fonte utilizada na mesma é reduzido. O que deveria ser uma indicação para orientação de um usuário acaba se tornando um "borrão" e ficando confusa. O tamanho mínimo ${ }^{5}$ é de $4,5 \mathrm{~cm}$, distanciando o usuário a $10 \mathrm{M}$.

\section{3: Posicionamento.}

Existem placas posicionadas em uma altura indevida, pois verticalmente são obstruídas por veículos estacionados. Ou seja, a altura de suas hastes de sustentação não dá alcance visual para a leitura de todas as informações.

\section{4: Padronização.}

A partir de uma breve pesquisa com o Departamento de Comunicação institucional, foi constatado que a demanda por identificação de sinalização era suprida quando havia a necessidade de indicação sazonal, como o local onde estava sendo realizado o vestibular, onde estava acontecendo a recepção de novos alunos ou algum seminário. Também eram confeccionadas placas para indicar novas construções ou para direcionar mudanças de localização de algum setor. Não havia, portanto, um projeto padronizado que criasse uma unidade visual entre as peças indicativas, fazendo com que tivessem tipos de fontes, tamanhos, cores e elementos visuais diferenciados entre elas.

\section{5: Adequação de Informações.}

Deparamos-nos no Campus com certos problemas de adequação de informações de algumas placas. Lugares de sumária importância mudam suas sedes e por isso as placas necessitam de alteração. $\mathrm{Na}$ configuração atual, essa mudança rotineira não é possível, pois ela é composta de placas de metal adesivadas, com as respectivas informações referentes à localização. $\mathrm{Na}$ necessidade de alteração, o projeto anterior deveria ser todo alterado.

\section{6: Materiais.}

Além do problema com a atualização dos dados, temos também o fato de que o tipo 
de vinil usado para o adesivo não é o mais indicado, pois com o passar do tempo e por efeito do clima, esse material vai se desgastando e a sinalização perde sua utilidade.

\section{Parte 2: Projeto.}

\section{1: Algumas mudanças de método.}

Por possuir o Centro Universitário de Volta Redonda um setor responsável em cuidar da imagem, qualquer solução desenvolvida deve respeitar padrões estéticos da sua identidade visual. O desenvolvimento do projeto de sinalização deveria respeitar não só a unidade institucional, mas também seguir trâmites administrativos de aprovação orçamentária e de defesa projetual. $\mathrm{O}$ ato de realizar um projeto envolvendo alunos e voltar para dentro da universidade não diferencia do procedimento metodológico (BAXTER: 1998) utilizado para atendimento de clientes, pois o processo de desenvolvimento deve passar por apresentação, cotação entre outras exigências.

\subsection{Definição das etapas de desenvolvimento.}

As etapas para desenvolvimento do sistema de sinalização seriam necessárias para que as tarefas fossem divididas entre os membros da equipe e para a definição de um cronograma mais enxuto, dentro das expectativas institucionais. (BAXTER: 1998)

O trabalho não tratava somente de uma análise de produto, mas também abrangia aspectos visuais. Por isso, habilidades de computação gráfica, redação e ilustração seriam necessárias à equipe. No início, eram apenas dois alunos, sendo um deles estagiário do centro Universitário e o outro, aluno voluntário. A partir das novas necessidades, foram trazidos para o grupo mais dois acadêmicos com outras expertises.

A partir da definição das etapas abaixo, as tarefas foram divididas entre o grupo:

\subsection{1: Fotografia do Campus Olezio Galotti}

Um dos membros envolvidos na equipe se encarregou de andar por todo o Campus e registrar todas as áreas fotograficamente. Então, foi possível identificar pontos críticos em sinalização, bem como prédios de maior fluxo diário de pessoas. Foram feitas cerca de 200 fotos, entre prédios e vias de acesso a eles.

\subsection{2: Definição de fluxos de circulação}

Um ponto importante a ser abordado é que a sinalização já existente no Centro Universitário seguia somente o fluxo de automóveis, pois para circular dentro do Campus, normalmente há uma via principal de mão única e ruas transversais de curta distância. Porém, para transitar dentro da instituição, o carro deve ser deixado em um dos estacionamentos que, por vezes, é distante do objetivo final do usuário, portanto, para as primeiras vezes que o sujeito circula, é difícil chegar ao ponto desejado sem que haja alguém que faça a indicação.

Logo, a partir de infográfico traçado com base em uma foto aérea e após a tomada fotográfica de todo o Campus, foi necessário traçar rotas de circulação automotiva e pedestre. (Figura 2)

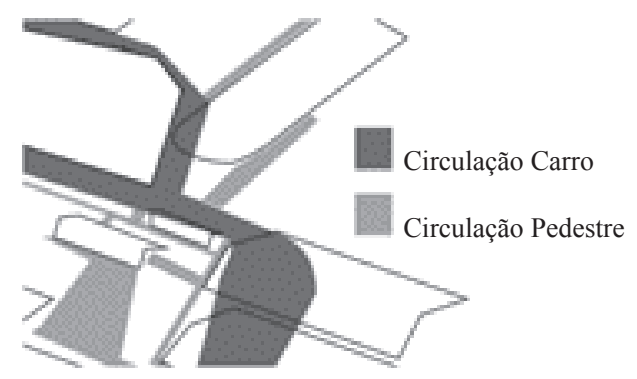

Figura 2: Fluxos de circulação

\subsection{3: Pontos de importância}

É possível afirmar que, em uma breve divisão de áreas, há espaços no infográfico que ocupam mais números de pontos de abordagem do que outros. Foi preciso definir a importância desses locais para uma posterior distribuição de placas. Os pontos foram divididos entre: informações gerais, específicas e de circulação interna. A terceira classificação foi separada da proposta, destinando a execução ao Departamento de Comunicação, até porque, parte do projeto já estava sendo feito. Foram posicionados, no 
infográfico, quadrados amarelos para placas de informações gerais que deveriam direcionar pontos para a esquerda e para a direita e quadrados menores azuis, que serviriam para as placas de informações específicas. Ligados a esses quadrados, fotos foram acondicionadas para que representassem melhor os locais.

\subsection{4: Pesquisa ergonômica e de legibilidade}

A partir do levantamento da problematização, foram feitos testes com usuários de diversas estaturas, criando- se uma relação com tamanhos de fontes e distanciamento. Foi definida para o projeto a fonte Helvetica, na altura de $4,5 \mathrm{~cm}$ a $5,0 \mathrm{~cm}$, pois é o padrão adotado pelo Conselho Nacional de Trânsito. Em um breve estudo antropométrico6, foi possível a definição da melhor altura para visualização pedestre e automotiva. (Figura 3)

Testes dentro de veículos em velocidade permitida para trânsito interno foram feitos a partir de uma amostragem entre funcionários, alunos e professores com os totens de simulação distribuídos pelo Campus.
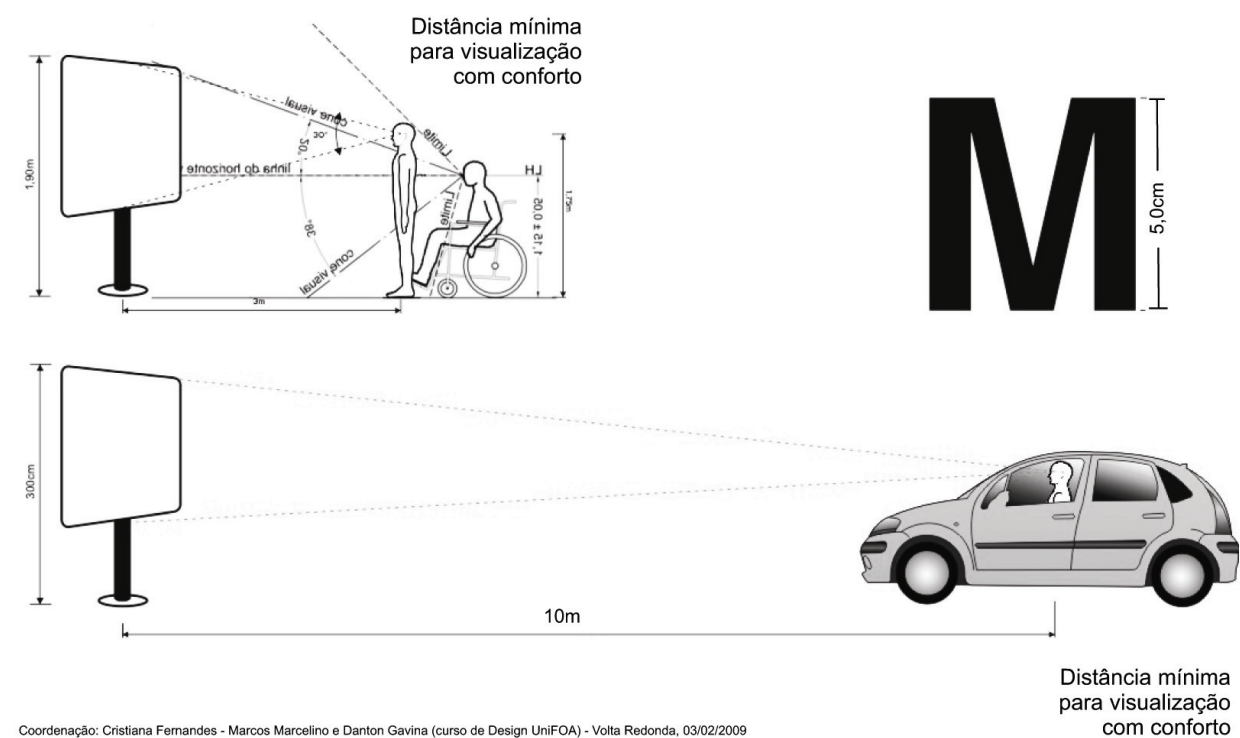

Figura 3: Pesquisa ergonômica de legibilidade

Foi definida a altura mínima de 2,90M para que as placas pudessem ser avistadas em uma distância mínima de 10M. As hastes de sustentação devem ter $1,20 \mathrm{M}$ e a área de abordagem, 1,50M. A largura para cada direção deve ter no máximo 1,20M, de forma que a distribuição das letras não ultrapasse 20 caracteres em caixa-alta.

Um dos dados apontados de dificuldade entre os usuários foi a localização das setas de indicaçãodedirecionamento.

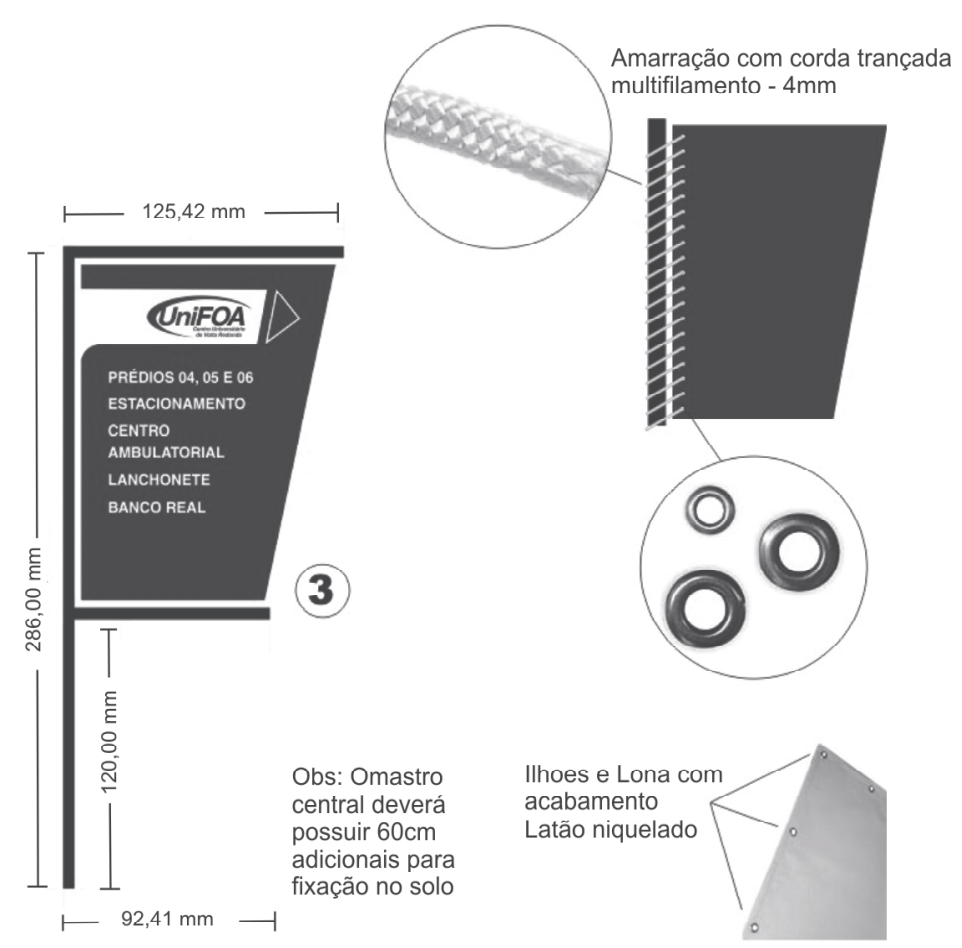


Dessa forma, o layout deveria ser o mais enxuto possível, criando uma unidade entre todos os elementos gráficos.

\subsection{5: Escolha de materiais}

Um dos pontos-chave apresentados pelos usuários foi a deterioração do material utilizado para a confecção das peças já existentes. Foram constatados casos de corrosão e desgaste do revestimento metálico. Isso se deve à má escolha do aço, que não seguia as indicações ABNT7.

Outro ponto importante é que a adesivação anteriormente feita, descolava-se facilmente, e, até em alguns casos, os elementos estavam derretidos pela exposição ao sol. Em outras observações, foi constatada depredação, principalmente nas placas posicionadas perto de áreas de convivência, dado que, aliás, foi fortemente abordado pelos funcionários pesquisados.

A melhor escolha para a solução dos problemas anteriormente abordados foi por uma alternativa que trabalhasse com um material de fácil confecção, ágil na troca de dados, resistente ao sol e ainda seguisse uma padronização visual institucional.

Definiu-se um modelo de totem de afixação, intitulado de "F", remetendo à inicial de FOA - Fundação Oswaldo Aranha, mantenedora do Centro Universitário, em tubos de aço carbono com pintura para exposição externa.

A partir daí, por levantamento junto aos fornecedores e recorrendo a soluções encontradas em projetos já publicados em catálogos e anuários, a escolha da lona vinílica com tratamento UV impressa em plotter, que é projetada para a duração de cinco anos, foi a mais indicada. Para uma possível troca de informações, que ocorre comumente em um Centro Universitário, a lona é substituída em apenas $10 \mathrm{~min}$, depois de 30min de impressão. Essa escolha também se deve ao fato de que a impressão, além de mais barata, fica menos exposta a depredações. Essa solução foi realmente difundida, com base no orçamento do projeto, que, entre as placas de chapa metálica e a lona, o custo cairia em cerca de $60 \%$ do valor. É certo que uma chapa de aço carbono, se fosse a opção de escolha, poderia ser reaproveitada. Porém, toda a lona descartada pela instituição é doada para uma cooperativa de artesanato.

O modo de afixação da lona na estrutura metálica foi definida por amarração com corda trançada multifilamento de $4 \mathrm{~mm}$. Para tanto, ilhoses de latão niquelado antiferrugem deveriam ser posicionados em torno de toda a extensão interna a $1,5 \mathrm{~cm}$ da borda. (Figura 4)

\subsection{6: Definição de layout e padronização visual}

As cores utilizadas não só pela identidade visual institucional, mas também adotadas para a sinalização interna, já desenvolvida pelo Departamento de Comunicação, são tons de azul com branco.

Testes feitos com usuários mostraram que, ao refletirem-se os faróis dos carros no adesivo reflexivo existente nas placas atuais, esses faziam sumir as informações, formando blocos luminosos que impediam a visualização do conteúdo. Por isso, o fundo azul, com as letras em branco, cria um contraste necessário para a compreensão dos dados a serem seguidos.

Para manter a unidade entre os dados e tornar enxuta a quantidade de elementos do layout, foi utilizado apenas um triângulo, simulando uma seta de direcionamento, já que a lona deveria ser cortada em diagonal, reforçando a ideia da direção.

Uma tarja branca foi estudada para adequação de numeração dos prédios, fazendo com que esse número se destaque do restante do conteúdo. Além disso, o "respiro" entre os elementos gráficos foi pensado de forma a melhorar a compreensão da mensagem.

\section{Parte 3: Conclusão}

O principal objetivo desse artigo foi documentar os resultados obtidos pelo projeto desenvolvido pelos alunos, sob a orientação 
de uma professora do curso de Design, que, preocupados com a qualidade de vida dos usuários do Campus Olezio Galotti, propuseram-se a contribuir com a prática projetual da área de Design. Além disso, as alternativas à problemática, encontradas durante o estudo, poderão dar abertura a outros projetos de várias aplicações.

Um ponto forte dos encontros, durante os dois meses e meio de projeto, foi a troca de experiências entre os membros da equipe, orientadora e professores que contribuíram para o desempenho acadêmico dos alunos na busca de soluções que melhor atendessem às expectativas.

Foi necessário o envolvimento do Departamento de Marketing institucional, da Assessoria da Presidência da mantenedora, da Prefeitura do Campus, do Comitê de Ética e do Comitê de biossegurança que, no momento, efetivavam projetos paralelos concorrentes com o caso em questão. Foram três reuniões decisórias de divisão de tarefas entre essas equipes de desenvolvimento.

Os encontros entre a equipe de desenvolvimento eram periódicos e planejados, cumprindo horários e respeitando a divisão de funções. Assim, foi possível o cumprimento de todas as metas estabelecidas no início do projeto.

$\mathrm{O}$ que facilitou a acessibilidade foi o fato de o Centro Universitário possuir clínicas de atendimento aos portadores de necessidades especiais, permitindo pesquisa desse tipo de usuário-visitante. Outro ponto facilitador foi o entendimento da necessidade e a colaboração dos funcionários.

Em uma fase bem avançada do desenvolvimento da proposta, foi marcado um encontro com o Reitor do Centro Universitário, o qual fez várias considerações cabíveis às mudanças no procedimento adotado. Foi verificado por ele que alguns setores listados para a execução das placas estavam com problemas de nomenclatura e de localização entre as áreas. Era uma fase de visita do MEC para recredenciamento institucional e a universidade deveria adequar-se às exigências presentes no Plano de Desenvolvimento Institucional de 20098. A partir daí o projeto deveria partir para um novo mapeamento, o que defasou o cronograma.

\section{Parte 4: Reformulando o infográfico}

Mais uma vez foi usada a foto aérea do Campus, e, junto ao Reitor, dessa vez no lugar de "cliente", foi feita uma nova delimitação de áreas e numeração dos prédios. Foi identificado que, a partir dessa verificação, as áreas foram reduzidas e, com isso, este reduziria o orçamento consideravelmente.

Foi feita uma reunião com a equipe e novas estratégias foram tomadas, identificando que o cliente deve ser envolvido durante todo o processo.

A forma de representação da foto não só deu outro direcionamento ao trabalho, mas também abriu a possibilidade de novos projetos a serem propostos posteriormente pelo curso de Design

1 - A estratégia adotada para atingir esse objetivo foi o apoio à participação de produtos brasileiros em premiações internacionais de design, já que, nesse segmento, os selos indicadores dessas premiações são uma forte garantia de diferenciais mercadológicos. Fonte: Design \& Excellence Brazil 2004/2005.

2 - Segundo a Wikipedia, Infografia ou infográficos são representações visuais de informação. Esses gráficos são usados onde a informação precisa ser explicada de forma mais dinâmica, como em mapas, jornalismo e manuais técnicos, educativos ou científicos. É um recurso muitas vezes complexo, podendo se utilizar da combinação de fotografia, desenho e texto.

3 - NositedaFundaçãoMAPFRE,aCirculação Viária é um conceito amplo que diz respeito não só ao trânsito de veículos e pedestres, mas também aos variados elementos que se relacionam no espaço público, determinando diferentes formas de mobilidade.

4 - É uma representação gráfica de um conjunto de fatores presentes nos locais de trabalho, capazes de acarretar prejuízos à saúde dos trabalhadores. Tais fatores se originam nos diversos elementos do processo de trabalho (materiais, equipamentos, instalações, suprimentos, e nos espaços de 
trabalho, onde ocorrem as transformações) e da forma de organização do trabalho (arranjo físico, ritmo de trabalho, método de trabalho, turnos de trabalho, postura de trabalho, treinamento etc.)

5 - Na Legislação do Conselho Nacional de Trânsito, há uma tabulação de distâncias $\mathrm{x}$ tamanhos de fontes que foram utilizadas no projeto. Fonte: DAER/RS.

6 - Fonte: Escala DIFFRIENT, N.;TILLEY, A. R.; HARMAN, D. Human Scale. (1981a e 1981b).

7 - Existem várias NBR, regras ABNT indicativas para sinalização externa. Algumas foram utilizadas no projeto, como NBR14890, que trata de sinalização vertical viária (requisitos) e NBR14962, que trata de placas (projeto e implantação).

8 - O Plano de Desenvolvimento Institucional funciona como um plano de ação, traçando metas a seremalcançadas durante $o$ ano. Quando citamos esse documento, avaliamos que os setores de atendimento ao aluno já estavam passando por processo de atendimento às condições de acessibilidade, como adequação de rampas de acesso, indicação por sinalização e disposição de vagas de estacionamento localizadas perto dessas áreas.

\section{Bibliografia}

1 - Disponível em : <http://pt.wikipedia.org/ wiki/Infografia $>$ Acesso em: 16/04/2008.

2 - Disponível em: <http://portal.mapfre.com. br/t265.jsp?idDocumento=17151 $>\quad$ Acesso em: 16/04/2008.

3 - MATTOS, U. A. ${ }^{\circ} \&$ FREITAS, N. B. B. Brazilian Risk Map: Limited Applicability of a WorkerModel. Cad. Saúde Pública, Rio de Janeiro, 10 (2): 251-258, abr/jun, 1994.

4 - HESKETT, J. The future of design. In: Design processes newsletter. Chicago, Institute of Design, IIT, 1993. Vol. 5, N 1-3,5.
5 - Disponível em $<$ http://www.designbrasil. org.br/portal/acoes/pbd_excelence.jhtml> Acesso em: 16/04/2008.

6 - UNIFOA.Centro Universitário de Volta Redonda. Projeto Pedagógico do Curso de Design.Volta Redonda, RJ, 2008.

7 - Disponível em:<www.redebrasil.inf. br/0anexos/anexoII_contran.pdf $>$ Acesso em: 16/04/2008.

8 - UNIFOA.Centro Universitário de Volta Redonda. Plano de Desenvolvimento Institucional.Volta Redonda, RJ, 2008.

9 - BAXTER, Mike. Projeto de produto: guia prático para design de novos produtos. 2. São paulo, Brasil: Edgard Blücher, 1998. 260p.

10 - DIFFRIENT, N.;TILLEY, A.E.; HARMAN, D.(1981a) Human Scale 4/5/6. Massachussetts: The MIT Press.

11 - NBR-14962 - Sinalização Vertical Viária - Suportes Metálicos em Aço para Placas - Projeto e Implantação. Rio de Janeiro, ABNT, 2003.

12 - NBR-14891 - Sinalização Vertical Viária - Placas. Rio de Janeiro, ABNT, 2002

\section{Endereço para Correspondência:}

Cristiana de Almeida Fernandes cristiana.fernandes@foa.org.br

Avenida dos trabalhadores, 420

Vila Santa Cecília - Volta Redonda - RJ

CEP: 27255-125

Informações bibliográficas:

Conforme a NBR 6023:2002 da Associação Brasileira de Normas Técnicas (ABNT), este texto científico publicado em periódico eletrônico deve ser citado da seguinte forma: FERNANDES, Cristiana de Almeida; MARCELINO, Marcos Vinícios Esteves da Silva; RODRIGUES, Danton Gravina Baêta; LIMA, Carla Fernandes de; PEREIRA, Matheus Moraes Amorim. Uma prática projetual de sinalização do Centro Universitário de Volta Redonda - UniFOA. Cadernos UniFOA. Volta Redonda, ano V, n. 12, abril 2010. Disponível em: $<$ http://www.unifoa.edu.br/cadernos/edicao/12/33.pdf $>$ 